\title{
The TPR-containing domain within Est1 homologs exhibits species-specific roles in telomerase interaction and telomere length homeostasis
}

\author{
David CF Sealey ${ }^{1}$, Aleksandar D Kostic ${ }^{1,3}$, Catherine LeBel ${ }^{1,4}$, Fiona Pryde ${ }^{2}$ and Lea Harrington ${ }^{1,2,5^{*}}$
}

\begin{abstract}
Background: The first telomerase-associated protein (Est1) was isolated in yeast due to its essential role in telomere maintenance. The human counterparts EST1A, EST1B, and EST1C perform diverse functions in nonsensemediated mRNA decay (NMD), telomere length homeostasis, and telomere transcription. Although Est1 and EST1A/ $B$ interact with the catalytic subunit of yeast and human telomerase (Est2 and TERT, respectively), the molecular determinants of these interactions have not been elaborated fully.

Results: To investigate the functional conservation of the EST1 protein family, we performed protein-protein interaction mapping and structure-function analysis. The domain in hEST1A most conserved between species, containing a TPR (tricotetrapeptide repeat), was sufficient for interaction of hEST1A with multiple fragments of hTERT including the N-terminus. Two mutations within the hTERT N-terminus that perturb in vivo function (NAAIRS $_{92}$, NAAIRS ${ }_{122}$ ) did not affect this protein interaction. ScEst1 hybrids containing the TPR of hEST1A, hEST1B, or hEST1C were expressed in yeast strains lacking EST1, yet they failed to complement senescence. Point mutations within and outside the cognate ScEst1 TPR, chosen to disrupt a putative protein interaction surface, resulted in telomere lengthening or shortening without affecting recruitment to telomeres.

Conclusions: These results identify a domain encompassing the TPR of hEST1A as an hTERT interaction module. The TPR of S. cerevisiae Est1 is required for telomerase-mediated telomere length maintenance in a manner that appears separable from telomere recruitment. Discrete residues in or adjacent to the TPR of Est1 also regulate telomere length homeostasis.
\end{abstract}

\section{Background}

In $S$. cerevisiae, telomeres are usually maintained by telomerase or RAD52-dependent recombination. The 'ever shorter telomere' genes EST1, EST2 (the telomerase reverse transcriptase, TERT), EST3, and TLC1 (the telomerase RNA) are essential for telomerase function because loss of any one gene results in progressive telomere shortening and senescence $[1,2]$. Mutation of $C D C 13$ - an essential gene - elicits similar consequences $[2,3]$. Rare "survivors" can bypass this senescence by maintaining telomeres through recombination. The homologous recombination factor Rad52 is important

\footnotetext{
* Correspondence: lea.harrington@umontreal.ca

'Department of Medical Biophysics, University of Toronto; Campbell Family Institute for Breast Cancer Research and Ontario Cancer Institute, University Health Network, Toronto, Ontario, Canada Full list of author information is available at the end of the article
}

for the generation of telomerase-independent Type I and Type II survivors in which telomeres are maintained by amplification of Y' elements or telomeric repeats, respectively; more rarely, survival can occur without Rad52 [4-10].

Cdc13 and Est1 are critical for the recruitment of the telomerase core complex (Est2-Tlc1) to telomeres in S phase [reviewed in [11-14]]. Cdc13 binds to singlestranded telomeric DNA $[15,16]$ and associates with telomeres throughout the cell cycle, with a peak in association during $S$ phase $[17,18]$. Est1 also binds to singlestranded telomeric DNA [19] and associates with telomeres in S phase $[17,18,20]$. Cdc13 and Est1 interact physically [21] and genetically, as evidenced by the unlinked complementation of $c d c 13-2$ and est1-60 alleles, each of which affects telomere maintenance and viability $[15,17,22,23]$. Several findings suggest that Est1
C Biomed Central 
recruits Est2 to the telomere in $\mathrm{S}$ phase by acting as an intermediary between $\mathrm{Cdc} 13$ and TLC1. For example, the telomere shortening and senescence that occur in the absence of EST1 are rescued by expression of a Cdc13-Est2 fusion protein [22]. Est1 binds to TLC1 [24-28], and the telomeric localization of Est2 in S phase is reduced when the region of TLC1 responsible for the Est1 interaction is deleted, or when EST1 is deleted [29].

In other organisms, Est1 homologs similarly associate with telomerase and regulate telomere length and stability, although in some instances their precise contributions to telomere function are still being uncovered. $S$. pombe Est1 associates with active telomerase in cell extracts, and est1- cells exhibit telomere shortening, senescence, and defects in chromosome end protection [30]. In C. albicans, telomere length in est1 $\Delta$ cells fluctuates over serial passages, suggesting that Est1 may repress homologous recombination at telomeres [31]. In humans, three Est1 homologs, hEST1A/SMG6, hEST1B/ SMG5 and hEST1C/SMG7 (hereafter referred to hEST1A, hEST1B and hEST1C) interact with chromatin and bind preferentially at telomeres [32-34]. Human EST1A and EST1B associate with active telomerase in cell lysates and in vitro [32,33]. Like ScEst1, hEST1A binds single-stranded telomeric DNA [33]. Transient over-expression (or depletion) of hEST1A causes telomere uncapping/end-to-end fusion and apoptosis, and stable over-expression of hEST1A in telomerase-positive cell lines elicits telomere shortening that can be mitigated by co-expression of hTERT [32-34].

Human EST1A, EST1B, and EST1C also possess functional homology to the C. elegans nonsense-mediated mRNA decay (NMD) factors SMG-6, SMG-5, and SMG-7 [32,33,35-38]. Transcripts containing premature termination codons (PTC) upstream of a terminal exonexon junction are degraded by nonsense-mediated mRNA decay (NMD) - a process involving the phosphorylation and dephosphorylation of UPF1 by SMG1 and PP2A, respectively [reviewed in $[39,40]]$. The three EST1 proteins form complexes with SMG1, UPF1, PP2A, and other components of the NMD pathway $[35,38]$, and mediate the dephosphorylation of UPF1 via recruitment of PP2A [35,38]. Depletion of hEST1A, hEST1B or hEST1C by RNA interference results in stabilization of PTC-containing mRNA $[37,41,42]$. Depletion of UPF1, SMG1, or hEST1A/SMG6 also leads to an increase in the intensity and number of foci containing the telomeric transcript TERRA [reviewed in [43]]. Parenthetically, the levels of $S$. cerevisiae Est1, Est2, Est3, Stn1, and Ten1 are regulated by NMD [44], but ScEst1 has no known role in NMD [42].

The complex functions of EST1 homologs are mirrored by their diversity in size and structure across species (Additional file 1, Figure S1). The region of highest homology among EST1 proteins includes tetratricopeptide repeat (TPR) consensus sequences [30-33] (Additional file 1, Figure S1). Typically, TPRs mediate protein-protein interactions [45]. The structure of hEST1C reveals a bona fide 14-3-3-like TPR comprised of alpha helices; several contiguous upstream alpha helices fold into a TPR-like structure despite the fact they lack a TPR repeat consensus sequence [46]. Upstream of the TPR, hEST1A contains an N-terminal DNA binding activity [[33,42]; Jen Cruickshank and Lea Harrington, unpublished], and the $\mathrm{N}$-terminus also interacts with hTR and other RNAs through an hTRinteraction domain (TRID) [47]. A region downstream of the hEST1B TPR resembles the DNA binding domain of ScEst1 [48], although DNA binding by hEST1B has not been described. Both hEST1A and hEST1B contain a C-terminal 'PilT N-terminal' (PIN) domain $[32,33,36,49]$. The PIN domain of hEST1A possesses a single-stranded RNA endonuclease activity and degrades PTC-containing mRNA $[49,50]$. The nuclease activity of the hEST1B PIN domain is greatly reduced likely due to the absence of critical residues in the active site [49]. This extensive cross-species complexity prompted us to conduct structure-function analysis of human and S. cerevisiae EST1 proteins using biochemical and genetic methods.

\section{Results}

Mapping the interactions between hEST1A and hTERT

Although it was known that hEST1A interacts with hTERT in vitro independently of hTR [33], and that TPRs typically mediate protein-protein interactions [45], it was unknown whether the TPR was sufficient for the interaction between hEST1A and hTERT. Fragments of hEST1A spanning all or part of the TPR (502-824, 334-824, 114-749, 114-780) proved unsuitable for in vitro interaction analysis as they precipitated non-specifically (Figure $1 \mathrm{C}$, and data not shown). An hEST1A fragment spanning a.a. 114-631 did not exhibit non-specific precipitation but failed to exhibit a significant interaction with hTERT fragments (Figure 1A, $\mathrm{B})$. Increasing the C-terminal boundary to fully encompass the minimal TPR domain spanning a.a 695-761 (to a.a. 824) resulted in a reproducible enrichment of hEST1A(114-824) onto anti-FLAG agarose in the presence of FLAG-hTERT fragments spanning amino acids 1-200, 1-350, 201-560, 601-1132, but not fragments spanning 201-350 or 350-560, a control protein (Akt), or mock translation reactions containing no input cDNA (Figure 1A-C). The hTERT-hEST1A interactions were not perturbed by micrococcal nuclease, indicating that they did not require nucleic acids (Figure $1 \mathrm{~A}, \mathrm{~B}$ ). Taken together, these data identify at least 


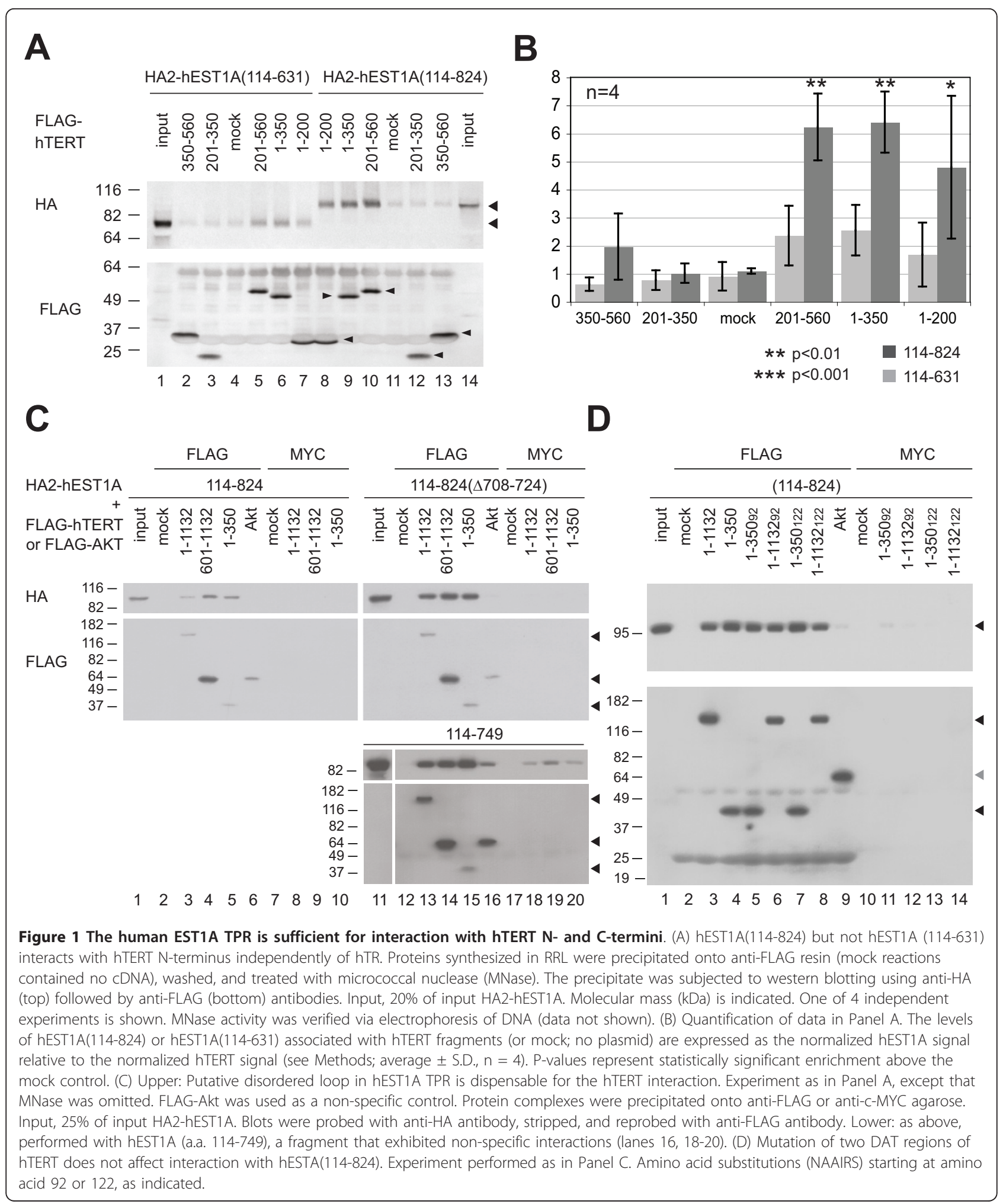

one interaction interface within hTERT(1-350) that includes residues beyond a.a. 200 that are important (but insufficient in the context of a.a. 201-350) for an interaction with hEST1A(114-824).
To further refine the hTERT protein interaction interface within the hEST1A TPR, we introduced various mutations within a.a. 551-785 of hEST1A(114-824) that we predicted to lie on the protein surface (see below), 
and tested these fragments for an hTR-independent interaction with hTERT(1-350) or hTERT(601-1132) (Additional file 1, Figure S2). None of the 22 introduced mutations, including the 17 residues mutated between hEST1A a.a. 631 and 824, perturbed the interaction of hEST1A(114-824) with either hTERT fragment (data not shown) [51]. In addition, removal of a sequence in hEST1A (a.a. 708-724) corresponding to a putative disordered loop in hEST1C [46] did not disrupt the hEST1A-hTERT interaction (Figure 1C). Thus, despite the existence of a putative hTERT interaction interface in hEST1A (631-824) that includes a TPR domain (695761 ), we were unable to identify residues within the TPR essential for this interaction.

We also tested the effect of mutations within the hTERT N-terminus on the interaction with hEST1A (114-824). Two DAT ("dissociates activities of telomerase") regions in hTERT, when substituted for six amino acids (NAAIRS) beginning at codons 92 or 122 [52-58], also proved dispensable for the interaction with hEST1A (114-824) (Figure 1D). DAT mutations have subtle effects on telomerase catalysis in vitro but dramatic deficits in telomere elongation and lifespan extension in vivo that can be partially rescued by fusion of hTERTDAT to POT1 or TRF2 [52-58]. Our data suggest this in vivo deficit is not the result of a perturbed interaction with hEST1A.

\section{Non-conservation of EST1 TPR function between species}

Recent data establish that hEST1C, of which the closest $S$. cerevisiae homolog is Ebs1, plays a similar role as Ebs1 in NMD [42]. Thus, we wished to determine if hEST1A or hEST1B might display functional similarity with ScEst1. Despite various strategies, we were unable to observe expression of full-length hEST1A, B, C in $S$. cerevisiae, which precluded analysis of whether human Est1 homologs might, alone or in combination, complement the senescence phenotype of strains lacking EST1. An alternate strategy was to test whether a region of Est1 containing the TPR could be "swapped" between species. Using an in vivo gap-repair cloning strategy in S. cerevisiae [59], the TPR of ScEst1 was replaced with the TPR of hEST1A, hEST1B or hEST1C or GFP(S65T) (the latter representing a similarly-sized domain as the TPR) (Additional file 1, Figure S3). The boundaries of the TPR were estimated according to the structurebased sequence alignment of EST1 homologs $[32,33,46]$. Specifically, the first nine alpha helices of hEST1C, or the corresponding region of hEST1A or hEST1B, were integrated into the corresponding region of ScEst1.

We first verified that est $1 \Delta$ and est $1 \Delta \operatorname{rad} 52 \Delta$ haploid strains generated from a diploid strain (S288C EST1/ est14::NAT RAD52/rad524::KAN) underwent senescence as expected $[1,8]$. Next, we tested the ability of low-copy
(pRS316) or high-copy (pRS426) hybrid Est1 expression plasmids (introduced into the EST1/est1A RAD52/ rad52 $2 \Delta$ strain prior to haploid selection) to rescue senescence in two separately isolated est $1 \Delta$ rad52 $\Delta$ haploid spores (Figure 2). Although the resultant TPR hybrid proteins were expressed (Figure 2B), neither the GFP(S65T)-Est1 hybrid nor any of the human TPR-Est1 hybrids proved sufficient to rescue senescence or maintain telomere length when spores were passaged every two days (Figure 2A, 3A, Additional file 1, Figure S4). Extension of the time between colony propagation from two days to four days, which promotes the rare survival (approximately 4-8\%) of populations lacking telomerase and RAD52 [6], also failed to permit complementation with the Est1 TPR hybrid proteins (Additional file 1, Figure S4). The TPR hybrids also failed to exert a dominant interfering effect on cell viability or telomere length maintenance in an EST1 rad52 $\Delta$ strain (Figure $2 \mathrm{~A}, \mathrm{C}$, Figure 3B, Additional file 1, Figure S4). Therefore, replacement of the cognate TPR of ScEst1 with the TPR of hEST1A, B, or C neither complemented nor interfered with wild-type ScEst1.

\section{Dissection of Est1 TPR function by mutagenesis}

Since the TPRs of hEST1A, B, or C were unable to function in place of the TPR of ScEst1, we mutated residues within and just outside the ScEst1 TPR domain and assessed effects on function in vivo. Selected residues that we predicted to be exposed to the concave surface of the putative protein-protein interaction interface (according to the alignment of the ScEst1 sequence to the hEST1C TPR structure) were changed to alanine [46] (Additional file 1, Figure S2); all mutants complemented the viability of est $1 \Delta$ rad52 $\Delta$ strains over multiple generations and did not interfere with viability in rad52 $\Delta$ strains (Figure 4A, B, Additional file 1, Figure S5). The average telomere length of cell populations expressing wild-type FLAG-tagged Est1 were compared with those expressing FLAG-tagged Est1 point mutants including Est1(F511S) - a mutant which confers viability in the absence of endogenous Est1 but maintains shorter-than-wild-type telomere lengths $[19,60]$ (Figure 4C, lanes 13-15, 28-30). Like cells expressing Est1 (F511S), cells expressing Est1(K84A/W87A/Q89A)FLAG exhibited slightly shorter telomeres (Figure 4C, lanes 19-21, 31-33). Unexpectedly, est1 $\Delta$ rad52 $\Delta$ cells containing certain Est1-FLAG mutants - namely E92A/ Q96A/W97A, R193A/N197A, S200A/F203A/Y204A, F243A/Q244A/K247A, N277A/N278A, or D281A/ T285A - exhibited longer telomeres than cells containing wild-type Est1-FLAG (Figure 4C). Telomere lengths appeared to slightly increase upon successive passages with certain mutants such as N277A/N278A, E92A/ Q96A/W97A and S200A/F203A/Y204A (Figure 4C, 


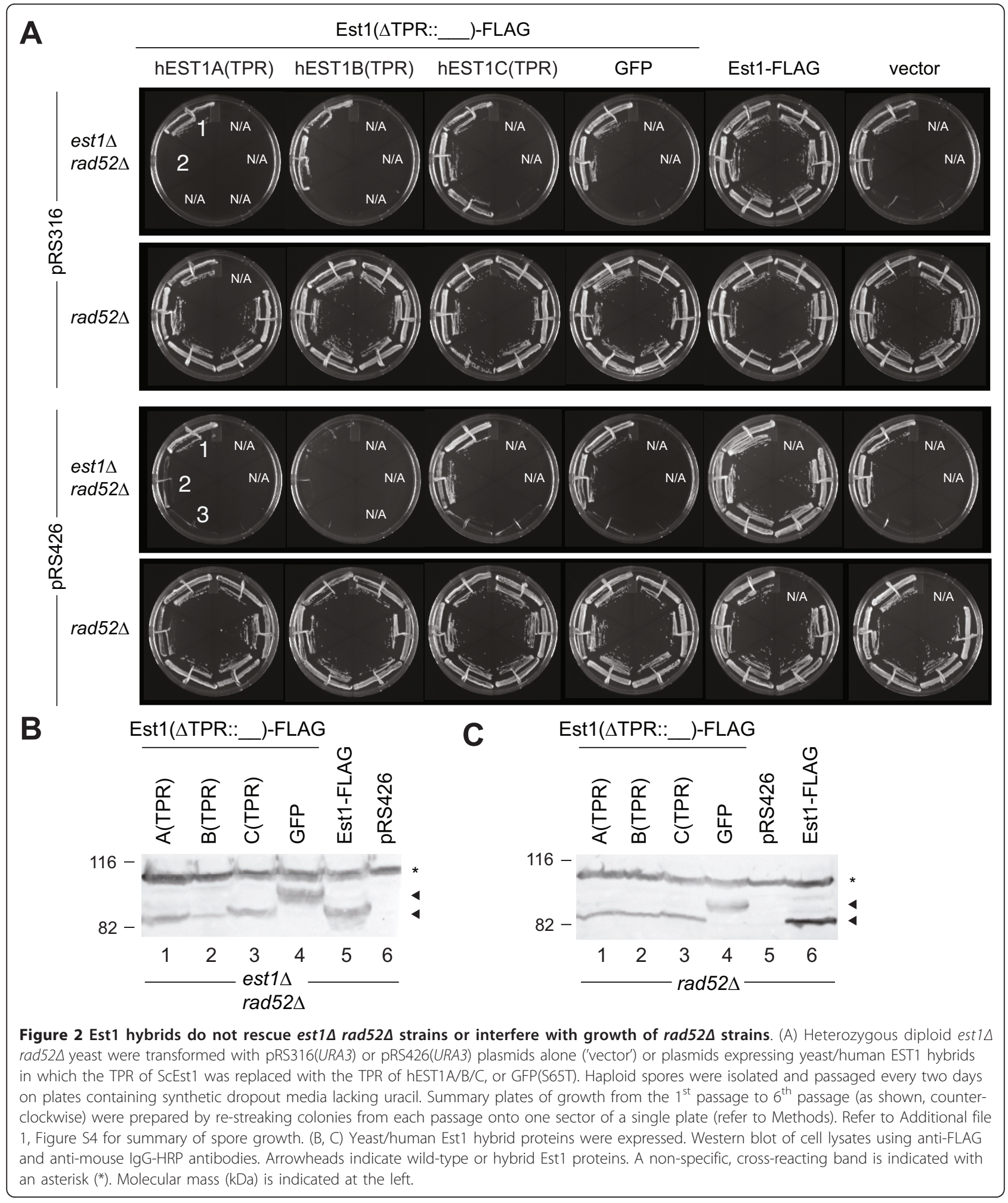

lanes 7-9, 22-24 or 35-36, and 25-27, respectively). The elongation phenotype was not due to overexpression of Est1, since telomere lengths in cells overexpressing wildtype Est1 (tagged or untagged) did not differ from strains lacking high-copy Est1 (Figure 5B). The differences in telomere lengths relative to wild-type Est 1 and to each other were reproducible with different strain isolates (data not shown). Although we did not test the 


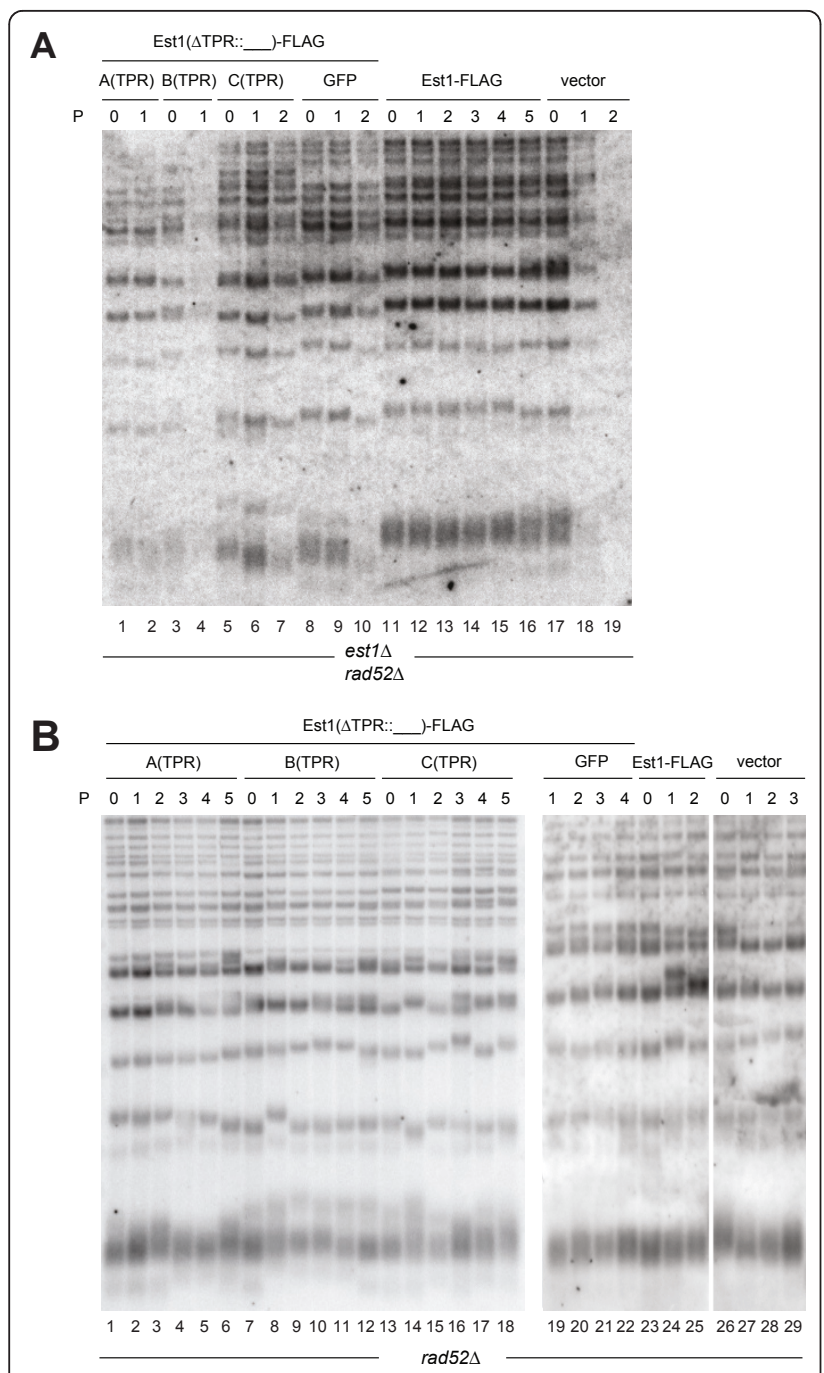

Figure 3 Est 1 hybrids do not maintain telomeres (est1 $\Delta$ $\operatorname{rad52\Delta )}$ or interfere with wild-type Est1 $(\operatorname{rad} 52 \Delta)$. Telomere DNA Southern blots. Genomic DNA isolated from est1 $\triangle$ rad52 2 (A) and rad52 $\Delta$ (B) cells at the indicated passages ( $P$; represented in Figure 2) was digested with Xhol. Strains expressed empty vector (pRS426; vector), wild-type Est1-FLAG, or Est1-FLAG hybrid proteins, as indicated. Telomeres were analyzed by Southern blotting using a (CACACCCA) 2 CC DNA probe. Lanes 1-18 and 19-28 represent different blots, and data between lanes 25-26 was omitted.

protein expression levels of all point mutants, larger perturbations in Est1 (e.g., the TPR 'swaps') did not alter Est1 levels relative to wild-type Est1-FLAG (Figure 2B). Thus, the different effects of TPR mutations on telomere length suggest that distinct residues in the vicinity or within the TPR domain function in telomere length maintenance, while other residues may function to limit telomere elongation.

The Est1-FLAG mutants were also tested for their effect on telomere length homeostasis in an EST1 $\operatorname{rad} 52 \Delta$ strain (Figure 4D, Additional file 1, Figure S5).
Est1(K84A/W87A/Q89A), which elicited shorter telomeres in an est1 $\Delta$ rad52 $\Delta$ background, did not elicit telomere attrition in the presence of wild-type Est1 (Figure 4D, lanes 17-19, 30-31). Expression of the Est1-FLAG mutants (R193A/N197A, F243A/Q244A/K247A, N277A/N278A, D281A/T285A, E92A/Q96A/W97A, or S200A/F203A/Y204A) in a rad52 $\Delta$ background resulted in slightly longer telomeres that persisted for five passages (Figure 4D). Thus, these mutants may interfere with an ability of wild-type Est1 to inhibit telomere elongation. Est1(F511S) led to shorter telomeres in a rad52 $\Delta$ background similar to the effect observed in a rad52 $\Delta$ est $1 \Delta$ strain (Figure $4 \mathrm{D}$, lanes 25-27), suggesting an ability of this mutation to interfere with wtEst1 function. The FLAG tag itself did not interfere with Est1 function, since telomeres in strains overexpressing Est1FLAG (in either a rad52 $2 \Delta$ or an est $1 \Delta$ rad52 $\Delta$ background) or untagged Est1 were maintained at a similar length as strains expressing only endogenous Est1 (Figure 4D, compare lane 13 with lanes 14-16 and Figure 4C, lanes 13-15, Figure 5B). Collectively, these data suggest that mutations within the Est1 TPR permitted complementation of est1 $1 \Delta$ cells; in some instances, concomitant telomere shortening or elongation was observed that suggested both positive and negative regulatory roles for the TPR in telomere length homeostasis.

Recruitment of Est1 point mutants to telomeric chromatin To test whether mutation of the Est1 TPR affected recruitment to the telomere, we performed chromatin immunoprecipitations (ChIP) experiments. Yeast lysates were subjected to crosslinking and sonication to obtain chromatin fragments approximately 500 bp in length, followed by immunoprecipitation onto anti-FLAG M2 resin. PCR analysis was performed using primers designed to amplify a single-copy genomic locus (ARS607) or the subtelomeric region of the right arm of chromosome X (tel XR). After normalization to both input genomic DNA and the ARS607 amplification signal, wild-type Est1-FLAG (Figure 5A, lanes 3, 6) exhibited a significant fold-enrichment at telomeric chromatin relative to same strain lacking ScEst1-FLAG (Figure 5A, lanes 1,4). We next tested three FLAGtagged Est1 mutants (K84A/W87A/Q89A, N277A/ N278A, F511S) for enrichment at telomeric chromatin in the est $1 \Delta$ rad52 $\Delta$ background. All three mutants exhibited telomeric enrichment similar to Est1-FLAG (Figure 5A). Notably, mutants associated with telomere elongation (N277A/N278A) or shortening (F511S, K84A/W87A/Q89A) exhibited equivalent enrichment. The similar levels of enrichment also suggest that fluctuations in telomere length are not simply due to changes in the level of Est1 protein recruited to telomeric heterohromatin (Figure 5B). These data suggest 

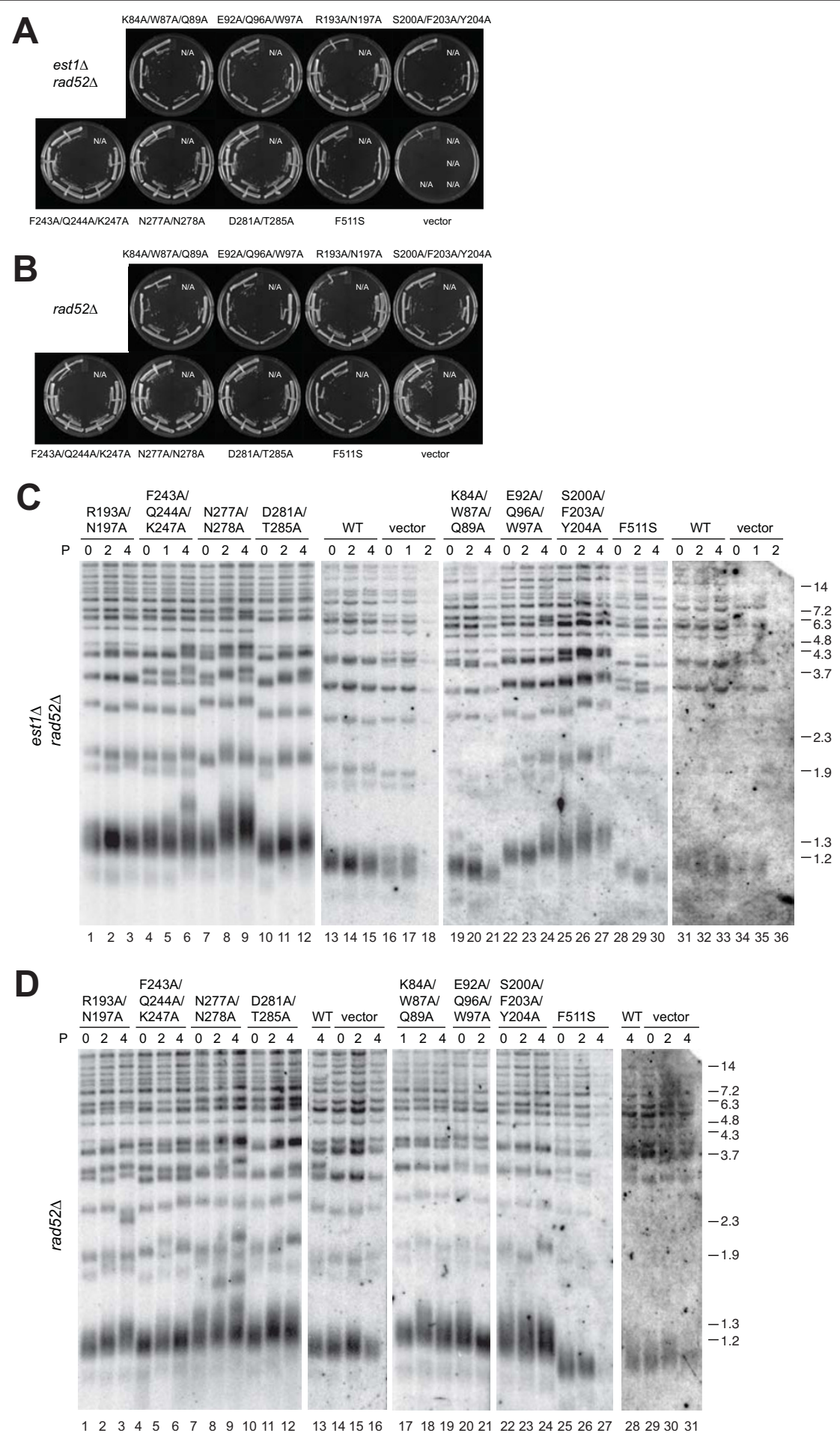

Figure 4 Mutation of the Est1 TPR does not compromise viability in S. cerevisiae but alters telomere length homeostasis. Heterozygous diploid est1 $\triangle$ rad52 $\triangle$ yeast were transformed with pRS426(URA3) plasmids expressing ScEst1-FLAG wild-type or indicated TPR mutants. Haploid est1 $\Delta$ rad52 $\Delta$ (A) and rad52 (B) spores were isolated and passaged every two days on plates containing synthetic dropout media lacking uracil. Refer to Additional file 1, Figure S5 for summary of spore growth. Telomere DNA Southern blots in haploid est1 $\Delta$ rad52 $\Delta$ (C) and rad52 (D) strains expressing empty vector (pRS426; vector), ScEst1-FLAG TPR mutants or wild-type Est1-FLAG, as indicated. Genomic DNA isolated from cells at the indicated passages ( $P$; represented in A, B) was digested with Xhol. Telomeres were analyzed by Southern blotting using a (CACACCCA $)_{2}$ CC DNA probe. In (C), two blots are represented by lanes 1-18, and 19-36; in (D), two blots are represented by lanes 1-16, and 1731. Gaps represent removal of redundant samples, or slight changes between contrast enhancement. DNA ladders are shown (kbp) at right. 
A

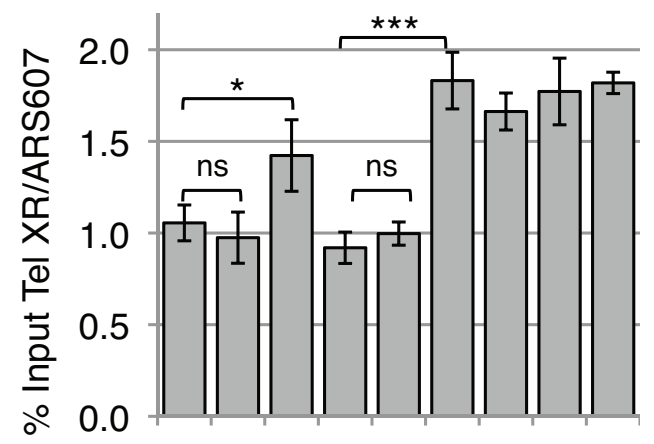

B

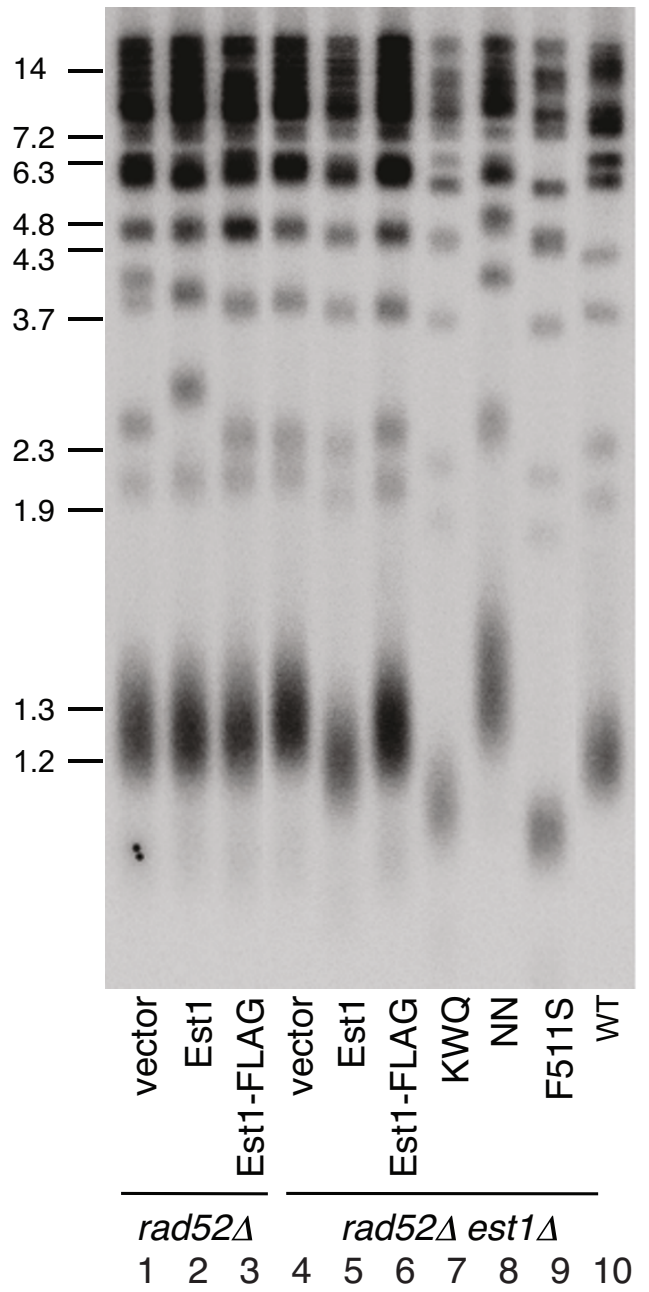

Figure 5 Mutation of the Est1 TPR does not interfere with recruitment to telomeric chromatin. Chromatin

immunoprecipitation of FLAG-tagged Est1 proteins (in pRS426) was performed as described in Methods. Enrichment of telomeric DNA was determined by comparing the intensity of PCR products generated using primer pairs matching a subtelomeric locus on chromosome X (tel XR) or another single-copy genomic locus (ARS607) and normalising to the values corresponding to input DNA. Data represent mean \pm S.D. for $n=4$ independent samples. Significant differences relative to the vector control (indicated by asterisks; $\left.{ }^{*} p<0.01,{ }^{* * *} p<0.0001\right)$ were determined by one-way ANOVA and the Tukey post-hoc test. Nomenclature: vector, pRS426 alone; Est1, untagged; Est1-FLAG; KWQ, Est1(K84AN87A/Q89A)FLAG; EQW, Est1(E92A/Q96A/W97A)-FLAG; NN, Est1(N277A/N278A)FLAG. (B) TRF analysis of the same strains as in (A); lane 10, S288C (WT). DNA markers at left in kbp. Note that average telomere lengths are longer in rad52 $\triangle$ strains (lanes 1-3) compared with WT (lane 10), as expected $[15,16]$. All samples were resolved on the same gel, and irrelevant or blank lanes between lanes 3, 4 and 9, 10 were removed.

that the effects on telomere length equilibrium conferred by the Est1 TPR mutants may involve steps downstream of recruitment to the telomere.

\section{Discussion}

Species-specific differences in the TERT-EST1 interaction Our observation that $\mathrm{N}$ - and $\mathrm{C}$-terminal regions of hTERT can interact with hEST1A (114-824) independently of hTR extends previous findings $[33,47]$. Redon et al. showed that an hTR-dependent interaction occurs between hTERT(147-311) and hEST1A(212-381), and that hTERT(147-311) may interact with hEST1A fragments beyond a.a. 212-502 independently of hTR [47] (Additional file 1, Figure S6). Collectively, our results suggest that hTERT forms protein-protein contacts with the TPR of hEST1A. As yet, the specific amino acids responsible for these interactions have not been identified. That the hEST1A TPR exhibits multiple contacts with discrete hTERT fragments is not without precedent; the hTERT amino-terminus (hTEN) also exhibits specific interactions with itself and the hTERT C-terminus, suggesting that an hEST1A interaction could be bridged by intramolecular hTERT interactions in vivo [56,61-63]. In addition, hTEN exhibits specific interactions with telomeric DNA and TPP1 that stimulate repeat addition processivity [64-68]. Taken together, these data underscore that multiple protein-protein and protein-DNA interaction interfaces serve to regulate hTERT function in vivo.

Like the interaction between hEST1A and hTERT, the interaction between Est1 and Est2 may involve both protein-protein and protein-RNA contacts. Est1 and Est2 interact with separate regions of Tlc1 [26-28,69], and Est1 does not co-purify with Est2 in a tlc1 $1 \Delta$ strain, suggesting that Tlc1 is required to assemble the telomerase complex [60]. However, recent findings suggest that recombinant ScEst1 stimulates telomerase activity even when the Tlc1-Est1 interaction is compromised, and that Tlc1 stimulates but is not required for an Est1Est2 interaction in RRL [70]. These results suggest that Est1 and telomerase may also interact through protein contacts. 
The TPR of ScEst1 may be involved in binding Tlc1. Mutations at residues that we predicted to reside on the convex surface of the domain (118/122/123 and 222/ 223/226) elicit telomere shortening and perturb association with Tlc1 [60]. None of the mutations that we introduced into the putative concave surface of the TPR of hEST1A reduced the interaction with hTERT. Mutagenesis of the convex surface of hEST1A TPR may yet identify an hTERT interaction interface.

The TPRs within hEST1C(1-497) and hEST1A(545785) bind a phosphopeptide within UPF1; these interactions are reduced by K66E/R163E and R625E/R706E mutations (on the concave surface), respectively, or by phosphatase treatment [46]. In our studies, the R625E/ R706E or D703/R706/Y707/Y724 mutations in hEST1A (114-824) did not disrupt the interactions with hTERT (1-350) or (601-1132). Since hTERT is phosphorylated by Akt and c-Abl in vivo [71,72], hEST1A may bind an as yet unmapped phosphomotif in hTERT. Alternatively, UPF1 and hTERT may interact with distinct interfaces of the hEST1A TPR. By analogy, in S. cerevisiae, components of the anaphase-promoting complex (Cdc16, Cdc23, and Cdc27) each contain multiple TPR repeats. Mutation of one TPR within Cdc27 impairs its interaction with $\mathrm{Cdc} 23$, but does not appreciably affect binding to Cdc16, or Cdc27 self-association [73].

\section{A role for the ScEst1 TPR in curtailing telomere elongation downstream of telomere binding}

We found that mutations within the ScEst1 TPR that affected telomere length equilibrium did not reduce the association of Est1 with telomeric heterochromatin in asynchronous cultures. Since Est1 recruitment to telomeres peaks in S phase $[17,18,20]$, further experiments in synchronized cultures may reveal further nuances of the influence of these mutations on the temporal regulation of telomere recruitment. The fact that the mutants showed a comparable enrichment to that of wild-type Est1 suggests that these ScEst1 TPR residues are nonetheless dispensable for an interaction with $\mathrm{Cdc} 13$, and is consistent with the notion that the perturbation of telomere length reflects a defect downstream of telomere recruitment.

While certain mutations predicted to disrupt the concave surface of the Est1 TPR elicited telomere shortening, other similarly predicted mutations elicited telomere elongation. The concave surface of the Est1 TPR may negatively regulate telomere length through an interaction with Ies3 - a component of the INO80 chromatin remodeling complex [74]. As demonstrated by yeast two-hybrid and co-immunoprecipitation experiments, Est 1 and Ies3 interact, and deletion of Ies3 results in telomere lengthening [74]. Mutation of three amino acids within the TPR of Est1 (G199A/P236A/
N278A) abolishes the Ies3 interaction [74]. This triple mutation impairs Tlc1 binding and elicits telomere shortening, thus precluding a direct assessment of the Ies3-Est1 interaction in telomere length regulation [74]. In contrast, we observed that alanine replacement of N277/N278 in Est1 led to telomere elongation. Thus, it is possible that the N277A/N278A mutation might disrupt interaction with Ies3 without perturbing Tlc1 association, which would support a direct role for the Ies3Est1 interaction in the negative regulation of telomere length by the INO80 complex [74]. Our results indicate that the TPR-containing region within ScEst1 positively and negatively regulates telomere length, and that the concave surface of the TPR domain appears important for Est1 function.

\section{Functional specialization of key cellular processes within and between species}

We observed that the TPRs of human EST1 proteins could not substitute for the ScEst1 TPR. Functional differences in other telomere-associated proteins have been noted across species. Two related 5'-3' helicases in $S$. cerevisiae, Pif1 and Rrm3, perform non-overlapping functions in inhibiting telomerase recruitment and promoting DNA fork progression, respectively [75], and both contribute to mitochondrial DNA stability in distinct ways $[76,77]$. In $S$. pombe, the single Pif1/Rrm3 ortholog Pfh1 is essential; some, but not all, of its diverse roles in mitochondrial, nuclear and telomere DNA replication are complemented by ScRrm3 [78-81]. In mammals, although the Pif1/Rrm3 ortholog interacts with telomerase, it is dispensable for viability, telomere length maintenance, and chromosome healing [82-84]. Similarly, Rif1 plays a critical regulatory role in telomere homeostasis in yeasts [reviewed in [14,85-89], while in mammals Rif1 modulates genome stability in response to DNA damage and appears dispensable for telomere length regulation [90-93].

In S. cerevisiae, the NMD-related function of EST1 homologs may have been delegated primarily to Ebs1, which shares the most sequence similarity (particularly in the TPR) with hEST1C [42]. Strains lacking EBS1 possess short telomeres [26] and, unlike est1 $\Delta$ strains, exhibit a defect in NMD [37,42]. Over-expression of hEST1C or Ebs1 in S. cerevisiae disrupts NMD [42]. In A. thaliana, EST1C/SMG7 is an essential gene with a role in NMD and meiotic cell cycle progression, but possesses no apparent role in telomere integrity or length regulation [94]. It will be interesting to determine whether mutations exist within the hEST1A TPR that selectively affect NMD or an interaction with hTERT. If a telomerase-specific interaction interface within hEST1A exists, it may represent an attractive target for telomerase inhibition in cancer since its short-term 
perturbation might spare other essential functions of EST1 related to telomere end protection or NMD.

\section{Conclusions}

A fragment of hEST1A of approximately 700 a.a. and encompassing the tetratricopeptide repeat (TPR, a.a. 695-761) was sufficient for nucleic acid-independent interactions with the N-terminus of hTERT (a.a. 1-350). The TPR of ScEst1 could not be complemented genetically by TPRs of the human Est1 homologs hEST1A, hEST1B, or hEST1C, suggesting that the former has evolved species-specific interactions that cannot be substituted by human EST1 TPRs. Mutagenesis within and just outside the ScEst1 TPR identified residues important for telomere length homeostasis but not recruitment to telomeric heterochromatin. Collectively, these data identify species-specific roles of the Est1 TPR domain in the recognition of hTERT and regulation of telomere length.

\section{Methods}

Co-immunoprecipitation of hTERT and hEST1A fragments and micrococcal nuclease treatment

pCR3-FLAG-hTERT-FLAG and pcDNA3.1-HA2hEST1A constructs were expressed in rabbit reticulocyte lysates (RRL) according to the manufacturer's instructions (Promega Corp.) in the absence of hTR. The inclusion of hTR RNA in hTERT translation reactions did not affect interactions with hEST1A (data not shown). Mock reactions contained no cDNA. Reactions were incubated separately for $90 \mathrm{~min}$ at $30^{\circ} \mathrm{C}$. Fifteen to 20 $\mu \mathrm{L}$ of each reaction was mixed in a total volume of 500 $\mu \mathrm{L}$ with cold CHAPS buffer (0.5\% w/v CHAPS, $10 \mathrm{mM}$ Tris-Cl pH 7.5, 10\% v/v glycerol, $100 \mathrm{mM} \mathrm{NaCl}, 1 \mathrm{mM}$ $\mathrm{MgCl}_{2} 1 \mathrm{mM}$ DTT, Roche EDTA-free Complete protease inhibitor cocktail) and agitated gently for $1 \mathrm{hr}$ at $4^{\circ} \mathrm{C}$. FLAG-tagged complexes were immunoprecipitated with pre-equilibrated anti-FLAG M2 agarose resin (Sigma). Anti-c-Myc agarose (BD Biosciences) was employed as a negative control resin. For micrococcal nuclease digestions, immunoprecipitates were washed twice with cold CHAPS buffer and treated with $40 \mathrm{U} / \mu \mathrm{L}$ micrococcal nuclease (New England Biolabs) at $30^{\circ} \mathrm{C}$ for $45 \mathrm{~min}$ in buffer containing $50 \mathrm{mM}$ Tris- $\mathrm{Cl} \mathrm{pH} \mathrm{7.9,5}$ $\mathrm{mM} \mathrm{CaCl}{ }_{2}$ and $1 \mathrm{mg} / \mathrm{mL}$ bovine serum albumin, or mock-treated in buffer without micrococcal nuclease. Reactions were terminated by the addition of excess EGTA, and immunoprecipitates were washed twice in cold CHAPS buffer. For experiments not involving micrococcal nuclease, immunoprecipitates were washed three times in cold CHAPS buffer.

Immunoprecipitates were boiled in SDS-PAGE loading dye. Proteins were resolved through $4-20 \% \mathrm{w} / \mathrm{v}$ TrisGlycine Novex gels (Invitrogen), transferred to PVDF membranes (Invitrogen), and subjected to immunoblotting with anti-HA-HRP (3F10; Roche). Where indicated, antibodies were removed by incubation in stripping buffer $(100 \mathrm{mM} \beta$-mercaptoethanol, $62.5 \mathrm{mM}$ Tris- $\mathrm{Cl} \mathrm{pH}$ $6.8,2 \% \mathrm{w} / \mathrm{v}$ SDS) for $10 \mathrm{~min}$ at $50^{\circ} \mathrm{C}$. Membranes were washed in $1 \mathrm{X}$ TBS containing $0.05 \% \mathrm{v} / \mathrm{v}$ tween 20 (BioRad), and re-blotted with mouse anti-FLAG M2 (Sigma) and sheep anti-mouse IgG-HRP (GE Healthcare), or anti-hTERT(RT domain) [95] and donkey antirabbit IgG-HRP (GE Healthcare). Blots were developed with ECL Plus (GE Healthcare) and exposed to film (Kodak) or captured using a Typhoon Trio variable mode imager.

In Figure 1B, immunoprecipitation data from four independent replicates of the experiment shown in Figure $1 \mathrm{~A}$ were quantified as follows. Firstly, the raw intensity of each hEST1A fragment (114-824 or 114-631) immunoprecipitated onto anti-FLAG resin was divided by the average intensity $(n=4)$ of the fragment in the mock immunoprecipitation lane (no added TERT). Secondly, the raw intensity of each hTERT fragment precipitated onto anti-FLAG resin was expressed as a ratio relative to the average intensity value of the same hTERT fragment $(\mathrm{n}=4)$. The normalized hEST1A value was divided by the normalized hTERT fragment value in each experiment, and the mean and standard deviation of these ratios is illustrated in Figure 1B. Statistical significance was determined by ANOVA analysis of the normalized ratios, assuming non-paired samples, and applying the Tukey post-hoc test for pairwise comparisons where confidence levels exceeded 95\%.

\section{Generation of yeast strains}

The diploid S288C est1 $::$ KAN/EST1 strain (MATa/ $\alpha$

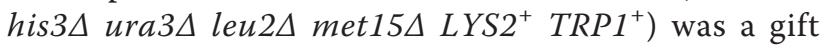
from Brenda Andrews (University of Toronto). The diploid was sporulated to obtain a haploid S288C est1 $1:$ : KAN strain (MATa). The KAN gene replacement cassette was substituted with a NAT cassette by transformation and appropriate selection to obtain S288C est $1 \triangle:: N A T$. This strain was crossed with a haploid S288C strain $(M A T \alpha)$ of the same genetic background to create a diploid S288C est1 $\triangle:: N A T / E S T 1$ strain. $R A D 52$ was deleted by transformation with a KAN gene replacement cassette followed by appropriate selection to obtain S288C est14::NAT/EST1 rad52A::KAN/RAD52. Gene deletions were verified by PCR and restriction enzyme digestion.

\section{Yeast expression vectors}

Open reading frames for hEST1A/SMG6 [GenBank: NM_001170957; hereafter referred to as hEST1A], hEST1B/SMG5 [GenBank:AY168922; hEST1B] and hEST1C/SMG7 variant 2 [GenBank:NM_201568; hEST1C] 
were cloned into low-copy (1-2 copies per cell) pRS316 (CEN6, ARS4, URA3) and high-copy ( 50 copies per cell) pRS426 (2 $\mu$ ori, REP3, FRT, URA3) expression plasmids $[96,97]$. pRS316 and pRS426 plasmids were obtained from Raymund Wellinger (University of Sherbrooke).

\section{Generation of yeast/human EST1 TPR hybrids}

The boundaries of the TPR were selected according to the structure-based alignment of EST1 sequences [32,33,46] (Additional file 1, Figure S3A). Plasmids encoding hybrid EST1 proteins in which the TPR of ScEst1 was replaced with the TPR of hEST1A, hEST1B, or hEST1C were generated by the in vivo gap-repair cloning method [59]. In the first step, pRS316(URA3)Est1-FLAG was digested with NruI and PflMI which cleaved the TPR coding sequence at unique restriction sites in the plasmid (Additional file 1, Figure S3B). In parallel, the sequence encoding the TPR of hEST1 was amplified by PCR using hybrid primers. The 5' ends of the forward primers contained $45 \mathrm{nt}$ of sequence identical to sense strand immediately upstream of ScEst1 codon 14 (the TPR sequence starts at codon 14). The 3' ends of the primers contained $30 \mathrm{nt}$ of sequence identical to the sense strand of the TPR coding sequence of hEST1A (starting at codon 551), hEST1B (codon 25), or hEST1C (codon 2). GFP(S65T) (amino acids 1-237) was also engineered in place of the TPR of ScEst1 as a control for disruption of the domain. The forward primers were as follows: Est1p13/hEST1A551, 5'-( $\left.\mathrm{PO}_{4}\right)$ GGCTTAATGGATAATGAAGAAGTTAACGAAGAATGTATGAGATTACACAGGCTTCTCCGGGT GGCTGACAACCAG-3'; Est1p13/hEST1B25, 5'-( $\left.\mathrm{PO}_{4}\right)$ GGCTTAATGGATAATGAAGAAGTTAACGAAGA ATGTATGAGATTACGGGCTGTGGTGGAGGCTG TGCATCGACTT-3'; Est1p13/hEST1C2, 5'-( $\left.\mathrm{PO}_{4}\right)$-GGC TTAATGGATAATGAAGAAGTTAACGAAGAATG TATGAGATTAAGCCTGCAGAGCGCGCAGTACC TCCGGCAG-3'; Est1p13/GFP, 5'-( PO $\left._{4}\right)$-GGCTTAATG GATAATGAAGAAGTTAACGAAGAATGTATGAG ATTAAGTAAAGGAGAAGAACTTTTCACTGGAG TT-3'. The 5' termini of the reverse primers contained $45 \mathrm{nt}$ of sequence identical to the antisense strand of ScEst1 immediately downstream of codon 289 (the TPR sequence ends at codon 289). The 3' termini of the primers contained $30 \mathrm{nt}$ of sequence identical to the antisense strand at the end of the TPR encoding sequence of hEST1A (upstream of, and including codon 785), hEST1B (codon 262), or hEST1C (codon 236). The reverse primers employed were as follows: Est1p290/ hEST1A785, 5'-( $\left.\mathrm{PO}_{4}\right)$-TTTTGACACAAGAATTGCCAATTTTTTCATCAGACGTCTTCTTTCCTTCCG CTTGGTCTCTTCAAACAAGCTCAT-3'; Est1p290/ hEST1B262, 5'-( $\left.\mathrm{PO}_{4}\right)$-TTTTGACACAAGAATTGCC AATTTTTTCATCAGACGTCTTCTTTCCATTTTG
GCTGCCTTGTCATACAGCCGCTT-3'; Est1p290/ hEST1C236, 5'-( $\left.\mathrm{PO}_{4}\right)$-TTTTGACACAAGAATTGCCAATTTTTTCATCAGACGTCTTCTTTCGCTTTCCAGTGCTTTAGAAAGTGCTTTTTG-3'; Est1p290/ GFP, 5'-( $\left.\mathrm{PO}_{4}\right)$-TTTTGACACAAGAATTGCCAATTT TTTCATCAGACGTCTTCTTTCTTTGTATAGTTCATCCATGCCATGTGTAAT-3'. Primers were obtained from Invitrogen. The gel-purified linearized plasmid DNA and PCR products were transformed into S. cerevisiae (haploid S288C est1 $1:$ NAT RAD52) and grown on solid SD media containing clonNAT (nourseothricin) (Werner BioAgents, Germany) to select for the est1 $\Delta$ genotype. The media also lacked uracil in order to select for gap repair of the linearized Est1 plasmid. The resultant plasmids were recovered using the Zymoprep II Yeast Plasmid Miniprep kit (Zymo Research) and amplified in E. coli via transformation and maxiprep (Qiagen). The coding sequences of the hybrid genes, including the junctions between human and yeast EST1 sequences, were verified by DNA sequencing. To create a set of pRS426 vectors, NotI/SalI fragments from the pRS316 vectors were ligated into the NotI/SalI sites of pRS426. The following hybrid genes were constructed: Est1(1-13)/hEST1A(551-785)/Est1 (290-699)-FLAG; Est1(1-13)/hEST1B(25-262)/Est1(290699)-FLAG; Est1(1-13)/hEST1C(2-236)/Est1(290-699)FLAG; and Est1(1-13)/GFP(S65T)/Est1(290-699)-FLAG.

\section{Manipulation and propagation of yeast on solid media}

Diploid yeast cultures were transformed according to a high-efficiency transformation protocol [98]. Diploids were sporulated on solid media, asci were digested with zymolyase, and haploid spores were dissected under a microscope using a microneedle (Singer, UK). Haploid spores of the desired genotype were streaked onto plates containing synthetic dropout media lacking uracil (SDURA) to select for maintenance of plasmids expressing the $U R A 3$ gene. After two or four days of growth at $30^{\circ} \mathrm{C}(\mathrm{P} 1$, passage 1 or approximately 20 generations), a single colony was re-streaked onto a second plate and incubated as described above (P2). Meanwhile, the P1 plate was stored at $4^{\circ} \mathrm{C}$. This scheme was continued until $\mathrm{P} 4$ or $\mathrm{P} 5$ plates were obtained. To demonstrate growth from P1-6, one colony from each "passage" plate stored at $4^{\circ} \mathrm{C}$ (including the starting haploid spore from the tetrad dissection plate) was re-streaked onto a sector of a "summary plate" which was then incubated at $30^{\circ} \mathrm{C}$ for a final two or four days. Plates were imaged on a Bio-Rad Molecular Imager Gel Doc XR System under white light. Images were captured below the point of signal saturation.

\section{Yeast protein extraction and western blotting}

Protein extracts were prepared as described [98]. Proteins were boiled in SDS-PAGE buffer, resolved through 
5\% w/v 29:1 acrylamide:bisacrylamide gels, transferred to PVDF membranes, and subjected to western blotting using mouse anti-FLAG M2 antibody (Sigma). Sheep anti-mouse IgG-HRP (GE Healthcare) was employed as secondary antibody. Blots were developed with ECL Plus reagents, and fluorescent signals were captured using a Typhoon Trio variable mode imager (GE Healthcare).

\section{Telomere length analysis by Southern blot}

A single colony growing on solid media was inoculated into $5 \mathrm{~mL}$ SD-URA and grown overnight at $26^{\circ} \mathrm{C}$. Cells were pelleted and genomic DNA was extracted and purified as described [99]. Genomic DNA $(5 \mu \mathrm{g})$ was digested with $\mathrm{XhoI}$ overnight at $37^{\circ} \mathrm{C}$. Restriction fragments were resolved through $0.7 \% \mathrm{w} / \mathrm{v}$ agarose gels at $45 \mathrm{~V}(2 \mathrm{~V} / \mathrm{cm})$. DNA was denatured in-gel by incubation with $0.5 \mathrm{M} \mathrm{NaOH}$ and $1.5 \mathrm{mM} \mathrm{NaCl}$, and neutralized in buffer containing $1.5 \mathrm{M} \mathrm{NaCl}$ and $0.5 \mathrm{mM}$ Tris$\mathrm{Cl} \mathrm{pH}$ 7.5. DNA was transferred to Hybond-N+ membranes in 20X SSC. Following transfer, membranes were rinsed in 2X SSC. Telomeric DNA was hybridized to a ${ }^{32} \mathrm{P} 5$ '-end-labeled (CACACCCA) ${ }_{2} \mathrm{CC}$ probe in Church buffer $\left(0.5 \mathrm{M} \mathrm{NaPO}_{4} \mathrm{pH} 7.2,1 \% \mathrm{w} / \mathrm{v} \mathrm{BSA}, 7 \% \mathrm{w} / \mathrm{v}\right.$ SDS, $1 \mathrm{mM}$ EDTA), then washed with $1 \mathrm{X}$ SSC/0.1\% w/v SDS. Membranes were exposed to a phosphorimager screen and scanned using a Typhoon Trio variable mode imager.

\section{Mutagenesis of hEST1A and ScEst1 TPRs}

The structure-based sequence alignment of the TPRlike/TPR of hEST1C/SMG7 and EST1 homologs $[32,33,46]$ was used as a guide to select residues in hEST1A(551-785) and ScEst1(14-289) that may be surface-exposed. The design of PCR primers for site-directed mutagenesis was aided by The Primer Generator [100] or SiteFind [101] and primers were obtained from IDT or Operon. The incorporation of the intended mutations into the respective cDNAs (and the absence of unwanted mutations) was confirmed by DNA sequencing.

\section{Chromatin immunoprecipitation}

Yeast cells were grown to logarithmic phase in liquid culture to an optical density (O.D. $600 \mathrm{~nm}$ ) of 1.0. Fifty $\mathrm{mL}$ of each culture was adjusted to $1 \% \mathrm{v} / \mathrm{v}$ formaldehyde (Sigma) and incubated at room temperature for $45 \mathrm{~min}$. The crosslinking reaction was terminated by addition of glycine to a final concentration of $135 \mathrm{mM}$. Samples were washed three times in ice cold $\mathrm{PBS}$ at $4^{\circ} \mathrm{C}$, and resuspended in $500 \mu \mathrm{L}$ FA buffer $(50 \mathrm{mM}$ Hepes $\mathrm{pH}$ 7.6, $140 \mathrm{mM} \mathrm{NaCl}, 1 \mathrm{mM}$ EDTA, $1 \% \mathrm{v} / \mathrm{v}$ Triton X-100, $0.1 \% \mathrm{v} / \mathrm{v} \mathrm{Na}$-deoxycholate, Roche EDTA-free Complete protease inhibitor cocktail) per 50 O.D.600 cells. Samples were sonicated for four cycles of $10 \mathrm{~s}$ followed by $30 \mathrm{~s}$ on ice, using a $3.2 \mathrm{~mm}$ microtip (VWR). Sonication resulted in fragmentation of chromatin to an average size of $500 \mathrm{bp}$ (range $300-800 \mathrm{bp}$ ) as determined by agarose gel electrophoresis. Two hundred $\mu \mathrm{L}$ sonicated lysate was incubated overnight at $4^{\circ} \mathrm{C}$ with anti-FLAGM2 agarose resin (Sigma). After extensive washing with FA buffer, complexes were eluted from beads using 300 $\mu \mathrm{g} / \mathrm{mL}$ FLAG peptide (Sigma). Cross-linked DNA was released by the addition of reverse cross-linking buffer (10 mM Tris $\mathrm{pH} 8,4 \mathrm{mM}$ EDTA, $100 \mathrm{mM} \mathrm{NaCl}$ ) and incubation at $65^{\circ} \mathrm{C}$ for $16 \mathrm{hr}$. Samples were then incubated for $3 \mathrm{hr}$ at $56^{\circ} \mathrm{C}$ after the addition of Proteinase $\mathrm{K}$ $(0.3 \mathrm{mg} / \mathrm{mL})$ and glycogen $(0.5 \mathrm{mg} / \mathrm{mL})$. DNA was extracted and PCR amplification was performed on approximately $10 \mathrm{ng}$ template DNA using primers specific to a unique subtelomeric sequence of chromosome XR (XR F: 5'-TACCCTGTCCCATTTCATTATACC-3', XR R: 5'-TACAAGTGCAAGTGAGTATGGCAT-3') or to an internal non-telomeric region at ARS607 (ARS607 F: 5'-GTGGTGATATAAACACTACATTCGC-3', ARS6 07 R: 5'-GCTTTCTAGTACCTACTGTGCCG-3'). PCR products were separated on a $6 \% \mathrm{w} / \mathrm{v}$ polyacrylamide gel in $1 \mathrm{X}$ TBE. The relative intensity of the subtelomerespecific PCR product was calculated using ImageQuant software (GE Healthcare). A region of interest containing each PCR product was defined, and the local average background signal was subtracted. The resultant subtelomere-specific values were then divided by a value for the corresponding internal loading control (ARS607), and expressed as a percentage of the signal generated from input DNA. In Figure 5, the ANOVA analysis was performed on sample values normalized to the values for the vector control strain within each experiment to enable between-experiment comparisons. By varying the concentration of DNA (in separate experiments), PCR reactions for ChIP samples and input DNA were determined to be in the linear range of amplification. Statistical analysis was carried out using GraphPad Prism 5.0, employing one-way ANOVA and Tukey's post-hoc test.

\section{Additional material}

Additional file 1: Supplementary Figures. Figure S1. Schematic representation of human and S. cerevisiae EST1 homologs. Figure S2: Comparative sequence analysis of EST1 at positions selected for mutation. Figure S3: Schematic representation of yeast/human Est1 hybrid proteins. Figure S4: Schematic representation of colony growth in Figure 2. Figure S5: Schematic representation of colony growth in Figure 4. Figure S6: Summary of hTERT/hEST1A co-IP experiments.

\section{List of abbreviations}

CHAPS: 3-(3-cholamidopropyl)dimethylammonio-1-propanesulfonate; ChIP: chromatin immunoprecipitation; EST: ever shorter telomeres; NMD: nonsense-mediated mRNA decay; P: passage; PIN: PilT N-terminal domain; PTC: premature termination codon; TERT: telomerase reverse transcriptase; 
TR: human telomerase RNA; TIc1: telomerase RNA; Sc: Saccharomyces cerevisiae; TBS: Tris-buffered saline; TPR: tetratricopeptide repeat; SDS: sodium dodecyl sulphate.

\section{Acknowledgements}

We thank Drs. Brenda Andrews and Raymund Wellinger for strains and plasmids, and Dawn Edmonds for assistance with strain construction. This work was supported by grants to LH from the Wellcome Trust (84637) and the Medical Research Council (G0800081). We thank T.W. Mak for transitional funding from the Campbell Family Institute for Breast Cancer Research. Members of the Harrington laboratory are thanked for critical discussion and comments on the manuscript.

\section{Author details}

${ }^{1}$ Department of Medical Biophysics, University of Toronto; Campbell Family Institute for Breast Cancer Research and Ontario Cancer Institute, University Health Network, Toronto, Ontario, Canada. ${ }^{2}$ Wellcome Trust Centre for Cell Biology, University of Edinburgh, Edinburgh, UK. ${ }^{3}$ Department of Pathology, Harvard Medical School, Boston, MA, USA. ${ }^{4}$ Samuel Lunenfeld Research Institute, Mount Sinai Hospital, Toronto, Ontario, Canada. ${ }^{5}$ Université de Montréal, Institute de Recherche en Immunologie et en Cancérologie, Montréal, Québec, Canada.

\section{Authors' contributions}

DCFS, CL and LH designed the experiments. ADK, DCFS, CL and FP performed the experiments. All authors analyzed the data. DCFS and LH wrote the manuscript. All authors read and approved the final manuscript.

Received: 7 June 2011 Accepted: 18 October 2011

Published: 18 October 2011

\section{References}

1. Lundblad V, Szostak JW: A mutant with a defect in telomere elongation leads to senescence in yeast. Cell 1989, 57(4):633-643.

2. Lendvay TS, Morris DK, Sah J, Balasubramanian B, Lundblad V: Senescence mutants of Saccharomyces cerevisiae with a defect in telomere replication identify three additional EST genes. Genetics 1996 144(4):1399-1412.

3. Weinert TA, Hartwell LH: Cell cycle arrest of cdc mutants and specificity of the RAD9 checkpoint. Genetics 1993, 134(1):63-80.

4. Grandin N, Charbonneau M: Telomerase- and Rad52-independent immortalization of budding yeast by an inherited-long-telomere pathway of telomeric repeat amplification. Mol Cell Biol 2009, 29(4):965-985.

5. Le S, Moore JK, Haber JE, Greider CW: RAD50 and RAD51 define two pathways that collaborate to maintain telomeres in the absence of telomerase. Genetics 1999, 152(1):143-152.

6. Lebel C, Rosonina E, Sealey DC, Pryde F, Lydall D, Maringele L, Harrington LA: Telomere maintenance and survival in saccharomyces cerevisiae in the absence of telomerase and RAD52. Genetics 2009, 182(3):671-684.

7. Lee JY, Mogen JL, Chavez A, Johnson FB: Sgs1 RecQ helicase inhibits survival of Saccharomyces cerevisiae cells lacking telomerase and homologous recombination. J Biol Chem 2008, 283(44):29847-29858.

8. Lundblad V, Blackburn EH: An alternative pathway for yeast telomere maintenance rescues est1- senescence. Cell 1993, 73(2):347-360.

9. Maringele $L$, Lydall D: Telomerase- and recombination-independent immortalization of budding yeast. Genes Dev 2004, 18(21):2663-2675.

10. Teng SC, Zakian VA: Telomere-telomere recombination is an efficient bypass pathway for telomere maintenance in Saccharomyces cerevisiae. Mol Cell Biol 1999, 19(12):8083-8093

11. Evans SK, Lundblad V: Positive and negative regulation of telomerase access to the telomere. J Cell Sci 2000, 113(Pt 19):3357-3364.

12. Vega LR, Mateyak MK, Zakian VA: Getting to the end: telomerase access in yeast and humans. Nat Rev Mol Cell Biol 2003, 4(12):948-959.

13. Taggart AK, Zakian VA: Telomerase: what are the Est proteins doing? Curr Opin Cell Biol 2003, 15(3):275-280

14. Smogorzewska A, de Lange T: Regulation of telomerase by telomeric proteins. Annu Rev Biochem 2004, 73:177-208.
15. Nugent $\mathrm{Cl}$, Hughes TR, Lue NF, Lundblad V: Cdc13p: a single-strand telomeric DNA-binding protein with a dual role in yeast telomere maintenance. Science 1996, 274(5285):249-252.

16. Lin JJ, Zakian VA: The Saccharomyces CDC13 protein is a single-strand TG1-3 telomeric DNA-binding protein in vitro that affects telomere behavior in vivo. Proc Natl Acad Sci USA 1996, 93(24):13760-13765.

17. Taggart AK, Teng SC, Zakian VA: Est1p as a cell cycle-regulated activator of telomere-bound telomerase. Science 2002, 297(5583):1023-1026.

18. Fisher TS, Taggart AK, Zakian VA: Cell cycle-dependent regulation of yeast telomerase by Ku. Nat Struct Mol Biol 2004, 11(12):1198-1205.

19. Virta-Pearlman V, Morris DK, Lundblad V: Est1 has the properties of a single-stranded telomere end-binding protein. Genes Dev 1996, 10(24):3094-3104.

20. Schramke V, Luciano P, Brevet V, Guillot S, Corda Y, Longhese MP, Gilson E, Geli V: RPA regulates telomerase action by providing Est1p access to chromosome ends. Nat Genet 2004, 36(1):46-54

21. Qi H, Zakian VA: The Saccharomyces telomere-binding protein Cdc13p interacts with both the catalytic subunit of DNA polymerase alpha and the telomerase-associated est1 protein. Genes Dev 2000, 14(14):1777-1788.

22. Evans SK, Lundblad V: Est1 and Cdc13 as comediators of telomerase access. Science 1999, 286(5437):117-120

23. Pennock E, Buckley K, Lundblad V: Cdc13 delivers separate complexes to the telomere for end protection and replication. Cell 2001, 104(3):387-396.

24. Lin JJ, Zakian VA: An in vitro assay for Saccharomyces telomerase requires EST1. Cell 1995, 81(7):1127-1135.

25. Steiner BR, Hidaka K, Futcher B: Association of the Est1 protein with telomerase activity in yeast. Proc Natl Acad Sci USA 1996, 93(7):2817-2821

26. Zhou J, Hidaka K, Futcher B: The Est1 subunit of yeast telomerase binds the Tlc1 telomerase RNA. Mol Cell Biol 2000, 20(6):1947-1955.

27. Livengood AJ, Zaug AJ, Cech TR: Essential regions of Saccharomyces cerevisiae telomerase RNA: separate elements for Est1 $p$ and Est2p interaction. Mol Cell Biol 2002, 22(7):2366-2374

28. Seto AG, Livengood AJ, Tzfati Y, Blackburn EH, Cech TR: A bulged stem tethers Est1p to telomerase RNA in budding yeast. Genes Dev 2002, 16(21):2800-2812.

29. Chan A, Boule JB, Zakian VA: Two pathways recruit telomerase to Saccharomyces cerevisiae telomeres. PLoS Genet 2008, 4(10):e1000236.

30. Beernink HT, Miller K, Deshpande A, Bucher P, Cooper JP: Telomere maintenance in fission yeast requires an est1 ortholog. Curr Biol 2003 13(7):575-580.

31. Singh SM, Steinberg-Neifach O, Mian IS, Lue NF: Analysis of telomerase in Candida albicans: potential role in telomere end protection. Eukaryot Cell 2002, 1(6):967-977.

32. Reichenbach $P$, Hoss $M$, Azzalin CM, Nabholz M, Bucher $P$, Lingner J: A human homolog of yeast Est1 associates with telomerase and uncaps chromosome ends when overexpressed. Curr Biol 2003, 13(7):568-574.

33. Snow BE, Erdmann N, Cruickshank J, Goldman H, Gill RM, Robinson MO, Harrington L: Functional conservation of the telomerase protein Est1p in humans. Curr Biol 2003, 13(8):698-704.

34. Azzalin CM, Reichenbach P, Khoriauli L, Giulotto E, Lingner J: Telomeric repeat containing RNA and RNA surveillance factors at mammalian chromosome ends. Science 2007, 318(5851):798-801.

35. Chiu SY, Serin G, Ohara O, Maquat LE: Characterization of human Smg5/ 7a: a protein with similarities to Caenorhabditis elegans SMG5 and SMG7 that functions in the dephosphorylation of Upf1. Rna 2003, 9(1):77-87.

36. Clissold PM, Ponting CP: PIN domains in nonsense-mediated mRNA decay and RNAi. Curr Biol 2000, 10(24):R888-890.

37. Gatfield D, Unterholzner L, Ciccarelli FD, Bork P, Izaurralde E: Nonsensemediated mRNA decay in Drosophila: at the intersection of the yeast and mammalian pathways. EMBO J 2003, 22(15):3960-3970.

38. Ohnishi T, Yamashita A, Kashima I, Schell T, Anders KR, Grimson A Hachiya T, Hentze MW, Anderson P, Ohno S: Phosphorylation of hUPF1 induces formation of mRNA surveillance complexes containing hSMG-5 and hSMG-7. Mol Cell 2003, 12(5):1187-1200.

39. Maquat LE: Nonsense-mediated mRNA decay: splicing, translation and mRNP dynamics. Nat Rev Mol Cell Biol 2004, 5(2):89-99.

40. Behm-Ansmant I, Kashima I, Rehwinkel J, Sauliere J, Wittkopp N, Izaurralde E: mRNA quality control: an ancient machinery recognizes and 
degrades mRNAs with nonsense codons. FEBS Lett 2007, 581(15):2845-2853.

41. Paillusson A, Hirschi N, Vallan C, Azzalin CM, Muhlemann O: A GFP-based reporter system to monitor nonsense-mediated mRNA decay. Nucleic Acids Res 2005, 33(6): :54.

42. Luke B, Azzalin CM, Hug N, Deplazes A, Peter M, Lingner J: Saccharomyces cerevisiae Ebs1p is a putative ortholog of human Smg7 and promotes nonsense-mediated mRNA decay. Nucleic Acids Res 2007, 35(22):7688-7697.

43. Luke B, Lingner J: TERRA: telomeric repeat-containing RNA. EMBO J 2009, 28(17):2503-2510.

44. Dahlseid JN, Lew-Smith J, Lelivelt MJ, Enomoto S, Ford A, Desruisseaux M, McClellan M, Lue N, Culbertson MR, Berman J: mRNAs encoding telomerase components and regulators are controlled by UPF genes in Saccharomyces cerevisiae. Eukaryot Cell 2003, 2(1):134-142.

45. Blatch $\mathrm{GL}$, Lassle $\mathrm{M}$ : The tetratricopeptide repeat: a structural motif mediating protein-protein interactions. Bioessays 1999, 21(11):932-939.

46. Fukuhara N, Ebert J, Unterholzner L, Lindner D, Izaurralde E, Conti E: SMG7 is a 14-3-3-like adaptor in the nonsense-mediated mRNA decay pathway. Mol Cell 2005, 17(4):537-547.

47. Redon S, Reichenbach P, Lingner J: Protein RNA and protein protein interactions mediate association of human EST1A/SMG6 with telomerase. Nucleic Acids Res 2007, 35(20):7011-7022.

48. Lundblad V: Telomere replication: an est fest. Curr Biol 2003, 13(11): R439-441.

49. Glavan F, Behm-Ansmant I, Izaurralde E, Conti E: Structures of the PIN domains of SMG6 and SMG5 reveal a nuclease within the mRNA surveillance complex. EMBO J 2006, 25(21):5117-5125.

50. Eberle $A B$, Lykke-Andersen $S$, Muhlemann $O$, Jensen TH: SMG6 promotes endonucleolytic cleavage of nonsense mRNA in human cells. Nat Struct Mol Biol 2009, 16(1):49-55.

51. Sealey DCF: Regulation of Telomerase by DNA and Protein Interactions. Toronto: University of Toronto; 2010.

52. Armbruster BN, Banik SS, Guo C, Smith AC, Counter CM: N-terminal domains of the human telomerase catalytic subunit required for enzyme activity in vivo. Mol Cell Biol 2001, 21(22):7775-7786.

53. Banik SS, Guo C, Smith AC, Margolis SS, Richardson DA, Tirado CA, Counter CM: C-terminal regions of the human telomerase catalytic subunit essential for in vivo enzyme activity. Mol Cell Biol 2002, 22(17):6234-6246.

54. Lee SR, Wong JM, Collins K: Human telomerase reverse transcriptase motifs required for elongation of a telomeric substrate. J Biol Chem 2003, 278(52):52531-52536

55. Moriarty TJ, Ward RJ, Taboski MA, Autexier C: An anchor site-type defect in human telomerase that disrupts telomere length maintenance and cellular immortalization. Mol Biol Cell 2005, 16(7):3152-3161.

56. Sealey DC, Zheng L, Taboski MA, Cruickshank J, Ikura M, Harrington LA: The $\mathrm{N}$-terminus of hTERT contains a DNA-binding domain and is required for telomerase activity and cellular immortalization. Nucleic Acids Res 2009.

57. Armbruster BN, Etheridge KT, Broccoli D, Counter CM: Putative telomererecruiting domain in the catalytic subunit of human telomerase. Mol Cell Biol 2003, 23(9):3237-3246.

58. Armbruster BN, Linardic CM, Veldman T, Bansal NP, Downie DL, Counter CM: Rescue of an hTERT mutant defective in telomere elongation by fusion with hPot1. Mol Cell Biol 2004, 24(8):3552-3561.

59. Rothstein R: Targeting, Disruption, Replacement, and Allele Rescue: Integrative DNA Transformation in Yeast. In Guide to Yeast Genetics and Molecular Biology. Edited by: Guthrie C, Fink GR. San Diego, CA: Academic Press; 1991:281-301.

60. Evans SK, Lundblad V: The Est1 Subunit of Saccharomyces cerevisiae Telomerase Makes Multiple Contributions to Telomere Length Maintenance. Genetics 2002, 162(3):1101-1115.

61. Arai K, Masutomi K, Khurts S, Kaneko S, Kobayashi K, Murakami S: Two independent regions of human telomerase reverse transcriptase are important for its oligomerization and telomerase activity. J Biol Chem 2002, 277(10):8538-8544

62. Beattie TL, Zhou W, Robinson MO, Harrington L: Functional multimerization of the human telomerase reverse transcriptase. Mol Cell Biol 2001, 21(18):6151-6160.
63. Moriarty TJ, Marie-Egyptienne DT, Autexier C: Functional organization of repeat addition processivity and DNA synthesis determinants in the human telomerase multimer. Mol Cell Biol 2004, 24(9):3720-3733.

64. Zaug AJ, Podell ER, Nandakumar J, Cech TR: Functional interaction between telomere protein TPP1 and telomerase. Genes Dev 2010, 24(6):613-622.

65. Jurczyluk J, Nouwens AS, Holien JK, Adams TE, Lovrecz GO, Parker MW, Cohen SB, Bryan TM: Direct involvement of the TEN domain at the active site of human telomerase. Nucleic Acids Res 2010, 39(5):1774-1788.

66. Robart AR, Collins K: Human Telomerase Domain Interactions Capture DNA for TEN Domain-Dependent Processive Elongation. Mol Cell 2011, 42(3):308-318

67. Rosenfeld KK, Ziv T, Goldin S, Glaser F, Manor H: Mapping of DNA Binding Sites in the Tetrahymena Telomerase Holoenzyme Proteins by UV CrossLinking and Mass Spectrometry. J Mol Biol 2011.

68. Steczkiewicz K, Zimmermann MT, Kurcinski M, Lewis BA, Dobbs D, Kloczkowski A, Jernigan RL, Kolinski A, Ginalski K: Human telomerase model shows the role of the TEN domain in advancing the double helix for the next polymerization step. Proc Natl Acad Sci USA 2011.

69. Hughes TR, Evans SK, Weilbaecher RG, Lundblad V: The Est3 protein is a subunit of yeast telomerase. Curr Biol 2000, 10(13):809-812.

70. DeZwaan DC, Freeman BC: The conserved Est1 protein stimulates telomerase DNA extension activity. Proc Natl Acad Sci USA 2009, 106(41):17337-17342.

71. Kang SS, Kwon T, Kwon DY, Do Sl: Akt protein kinase enhances human telomerase activity through phosphorylation of telomerase reverse transcriptase subunit. J Biol Chem 1999, 274(19):13085-13090.

72. Kharbanda S, Kumar V, Dhar S, Pandey P, Chen C, Majumder P, Yuan ZM, Whang Y, Strauss W, Pandita TK, et al: Regulation of the hTERT telomerase catalytic subunit by the c-Abl tyrosine kinase. Curr Biol 2000, 10(10):568-575.

73. Lamb JR, Michaud WA, Sikorski RS, Hieter PA: Cdc16p, Cdc23p and Cdc27p form a complex essential for mitosis. Embo J 1994, 13(18):4321-4328.

74. Yu EY, Steinberg-Neifach O, Dandjinou AT, Kang F, Morrison AJ, Shen X, Lue NF: Regulation of telomere structure and functions by subunits of the INO80 chromatin remodeling complex. Mol Cell Biol 2007, 27(16):5639-5649.

75. Bochman ML, Sabouri N, Zakian VA: Unwinding the functions of the Pif 1 family helicases. DNA Repair (Amst) 2010, 9(3):237-249.

76. O'Rourke TW, Doudican NA, Zhang H, Eaton JS, Doetsch PW, Shadel GS: Differential involvement of the related DNA helicases Pif1 $p$ and Rrm3p in mtDNA point mutagenesis and stability. Gene 2005, 354:86-92.

77. Cheng $X$, Qin Y, Ivessa AS: Loss of mitochondrial DNA under genotoxic stress conditions in the absence of the yeast DNA helicase Pif1p occurs independently of the DNA helicase Rrm3p. Mol Genet Genomics 2009, 281(6):635-645.

78. Pinter SF, Aubert SD, Zakian VA: The Schizosaccharomyces pombe Pfh $1 \mathrm{p}$ DNA helicase is essential for the maintenance of nuclear and mitochondrial DNA. Mol Cell Biol 2008, 28(21):6594-6608

79. Ryu GH, Tanaka H, Kim DH, Kim JH, Bae SH, Kwon YN, Rhee JS, MacNeill SA, Seo YS: Genetic and biochemical analyses of Pfh1 DNA helicase function in fission yeast. Nucleic Acids Res 2004, 32(14):4205-4216.

80. Tanaka H, Ryu GH, Seo YS, Tanaka K, Okayama H, MacNeill SA, Yuasa Y: The fission yeast pfh $1(+)$ gene encodes an essential $5^{\prime}$ to $3^{\prime}$ DNA helicase required for the completion of S-phase. Nucleic Acids Res 2002, 30(21):4728-4739.

81. Zhou JQ, Qi H, Schulz VP, Mateyak MK, Monson EK, Zakian VA: Schizosaccharomyces pombe pfh $1+$ encodes an essential $5^{\prime}$ to $3^{\prime}$ DNA helicase that is a member of the PIF1 subfamily of DNA helicases. Mol Biol Cell 2002, 13(6):2180-2191.

82. Mateyak MK, Zakian VA: Human PIF helicase is cell cycle regulated and associates with telomerase. Cell Cycle 2006, 5(23):2796-2804.

83. Snow BE, Mateyak M, Paderova J, Wakeham A, lorio C, Zakian V, Squire J, Harrington L: Murine Pif1 interacts with telomerase and is dispensable for telomere function in vivo. Mol Cell Biol 2007, 27(3):1017-1026.

84. Reynolds GE, Gao Q, Miller D, Snow BE, Harrington LA, Murnane JP: PIF1 disruption or NBS1 hypomorphism does not affect chromosome healing or fusion resulting from double-strand breaks near telomeres in murine embryonic stem cells. DNA Repair (Amst) 2011. 
85. Kanoh J, Ishikawa F: spRap1 and spRif1, recruited to telomeres by Taz1, are essential for telomere function in fission yeast. Curr Biol 2001, 11(20):1624-1630.

86. Levy DL, Blackburn EH: Counting of Rif1p and Rif2p on Saccharomyces cerevisiae telomeres regulates telomere length. Mol Cell Biol 2004 24(24):10857-10867.

87. Teixeira MT, Arneric M, Sperisen P, Lingner J: Telomere length homeostasis is achieved via a switch between telomerase- extendible and -nonextendible states. Cell 2004, 117(3):323-335.

88. Miller KM, Ferreira MG, Cooper JP: Taz1, Rap1 and Rif1 act both interdependently and independently to maintain telomeres. Embo J 2005, 24(17):3128-3135.

89. Castano I, Pan SJ, Zupancic M, Hennequin C, Dujon B, Cormack BP: Telomere length control and transcriptional regulation of subtelomeric adhesins in Candida glabrata. Mol Microbiol 2005, 55(4):1246-1258.

90. Adams IR, McLaren A: Identification and characterisation of mRif1: a mouse telomere-associated protein highly expressed in germ cells and embryo-derived pluripotent stem cells. Dev Dyn 2004, 229(4):733-744.

91. Buonomo SB, Wu Y, Ferguson D, de Lange T: Mammalian Rif1 contributes to replication stress survival and homology-directed repair. J Cell Biol 2009, 187(3):385-398

92. Silverman J, Takai H, Buonomo SB, Eisenhaber F, de Lange T: Human Rif1, ortholog of a yeast telomeric protein, is regulated by ATM and 53BP1 and functions in the S-phase checkpoint. Genes Dev 2004, 18(17):2108-2119.

93. Xu L, Blackburn EH: Human Rif1 protein binds aberrant telomeres and aligns along anaphase midzone microtubules. J Cell Biol 2004, 167(5):819-830.

94. Riehs N, Akimcheva S, Puizina J, Bulankova P, Idol RA, Siroky J, Schleiffer A, Schweizer D, Shippen DE, Riha K: Arabidopsis SMG7 protein is required for exit from meiosis. J Cell Sci 2008, 121(Pt 13):2208-2216.

95. Oulton R, Harrington L: A human telomerase-associated nuclease. Mol Biol Cell 2004, 15(7):3244-3256.

96. Sikorski RS, Hieter P: A system of shuttle vectors and yeast host strains designed for efficient manipulation of DNA in Saccharomyces cerevisiae. Genetics 1989, 122(1):19-27.

97. Christianson TW, Sikorski RS, Dante M, Shero JH, Hieter P: Multifunctional yeast high-copy-number shuttle vectors. Gene 1992, 110(1):119-122.

98. Amberg D, Burke D, Strathern J: Methods in Yeast Genetics. Cold Spring Harbor, New York: Cold Spring Harbor Laboratory Press; 2005.

99. LeBel C, Larrivee M, Bah A, Laterreur N, Lvesque N, Wellinger RJ: Assessing telomeric phenotypes. Methods Mol Biol 2006, 313:265-316.

100. Turchin A, Lawler JF Jr: The primer generator: a program that facilitates the selection of oligonucleotides for site-directed mutagenesis. Biotechniques 1999, 26(4):672-676

101. Evans PM, Liu C: SiteFind: a software tool for introducing a restriction site as a marker for successful site-directed mutagenesis. BMC Mol Biol 2005, 6:22.

doi:10.1186/1471-2199-12-45

Cite this article as: Sealey et al:: The TPR-containing domain within Est1 homologs exhibits species-specific roles in telomerase interaction and telomere length homeostasis. BMC Molecular Biology 2011 12:45.

\section{Submit your next manuscript to BioMed Central and take full advantage of:}

- Convenient online submission

- Thorough peer review

- No space constraints or color figure charges

- Immediate publication on acceptance

- Inclusion in PubMed, CAS, Scopus and Google Scholar

- Research which is freely available for redistribution

Submit your manuscript at www.biomedcentral.com/submit 